\title{
A study of the vesical ganglia in children and the relationship to the megaureter megacystis syndrome and Hirschsprung's disease
}

\author{
SIDNEY LEIBOWITZ ${ }^{1}$ AND MARTIN BODIAN \\ From the Department of Morbid Anatomy, The Hospital for Sick Children, \\ Great Ormond Street, London
}

SYNOPSIS A method for the assay of vesical ganglion cells is described and the number and dis- $-\dot{-}$ tribution of the neurones in three normal bladders was studied. Vesical ganglion counts were done in cases of the megaureter-megacystis syndrome, megaureter, bladder neck obstruction, megacystiso associated with absent abdominal muscles, Hirschsprung's disease, and lumbar myelomeningocoele. A normal complement of neurones was found in each case.

No evidence was found that the megaureter-megacystis syndrome is due to an agenesis of the peripheral autonomic ganglia similar to that in Hirschsprung's disease. Vesical ganglia were normale in the two cases examined and no clinical association was found between the two conditions in ac large series of cases. Moreover, a study of the cell counts suggests that at least some of the reports of such a lesion are based upon an inadequate appreciation of the number and distribution of neurones in the normal urinary tract.

Megaureter by definition is a dilatation of the ureters in which no anatomical obstruction to the flow of urine can be demonstrated. Attempts have therefore been made to explain the condition as a primary disturbance of muscle or of the autonomic nervous system. Suggestions have included achalasia at the uretero-vesical junction (Hurst and Gaymer Jones, 1931), spasm of the lower ureter (Hepler, 1937), sympathetic overactivity (Learmonth, 1931), and a degeneration of the peripheral autonomic neurones (Ruland, 1956; Etzel, 1942).

Many authors draw an analogy between megaureter, megaoesophagus, and megacolon, and there have been repeated claims for a clinical association between megaureter and Hirschsprung's disease. The absence of intramural ganglion cells in the bowel in the latter condition suggested that a similar defect in the urinary tract might account for megaureter.

Lewis and Kimbrough (1952) postulated a lesion of this type at the lower end of the ureter. They regarded the relatively narrow juxtavesical portion found in some cases as an aganglionic, aperistaltic

'Present address: The Department of Pathology, Guy's Hospital, London, S.E.

Received for publication 30 January 1963. segment constituting an obstruction at that point. The major objection to this explanation is the virtuab absence of intramural ganglion cells from the normab ureter. Peristalsis in this organ is not dependent ono a local nerve reflex, as in the gut, but is mediated by an impulse conducted in the muscle layer alone. (Prosser, Smith, and Melton, 1955). Nevertheless, the theory is still widely quoted.

Swenson et al. (1952) and Swenson and Fisher (1955) have suggested that the ganglion cell defect is not in the ureter itself but in the bladder. According tor this view both megaureter and Hirschsprung' $\$$ disease are due to an abnormality in the development of the pelvic parasympathetic nervous system N Not all forms of megaureter are considered to be due to this cause, but only those associated with क large bladder capacity and a characteristic cysto 5 metric curve. Both clinical and cystometric data have been adduced in support of this view, but the theory rests mainly upon the histological evidence Sections of the bladder wall were examined and if ${ }^{+}$ was claimed that ganglia were either completely absent or very considerably reduced in number. $A+$ similar absence of vesical ganglia has been reported in megacystis in adults (Trassord, 1959) and in twळ cases associated with absent abdominal muscles ip children (Henley and Hyman, 1953). 
It is difficult to assess the significance of variations in the number of ganglion cells in sections from an organ, such as the bladder, which is subject to large fluctuations in size and shape. An added complication is that the nerve cells are not evenly distributed but form a pattern of innervation which, although constant, is highly irregular.

The purpose of the present investigation was to re-examine this problem by means of a study of the ganglion cell distribution in the normal bladder; the development of a method for the comparison of ganglion cell counts in bladders of varying size; the comparison of counts in the megauretermegacystis syndrome, in several other examples of pathological bladders, in cases of Hirschsprung's disease, and in controls.

\section{THE MEGAURETER-MEGACYSTIS SYNDROME}

An initial difficulty is presented by the definition of the terms 'megaureter' and 'megacystis'. Megaureter is essentially diagnosed by a process of exclusion in which all the known causes of ureteral dilatation are eliminated. These include valvular and other obstructive lesions of the urethra, neurogenic disorders of the bladder due to anomalies of the spinal cord, and a long list of uncommon obstructive lesions such as ureterocoele and neoplasm. Ureteric dilatation is also found in association with ectopia, reduplication, and other gross developmental malformations of the urinary tract. Of the remaining cases a proportion will be found to show some evidence of obstruction at the vesical outlet. Bladder neck obstruction, bladder neck fibrosis (Marion's disease), and urethral fibroelastosis (Bodian, 1957) are terms which have been applied to this condition and which reflect differing views on the pathology. The main clinical features are difficulty of micturition, retention, varying degrees of trabeculation, and prominence of the bladder neck. In some cases the capacity of the bladder is increased and the cystometric curve may be indistinguishable from that in the megaureter-megacystis syndrome. Swenson et al. (1952) include some cases with prominence of the bladder neck among the megacystis group.

When all these causes of ureteric dilatation have been considered, a residual group, megaureter, remains. On clinical and cystometric grounds a distinction has been made between simple megaureter, in which the capacity of the bladder is normal, and megaureter associated with megacystis (Williams 1958). All attempts, however, to define the term megacystis accurately are defeated by the limitations of the cystometric technique, lack of information on the normal cystometrogram in children, and the difficulty of measuring bladder volume in the presence of reflux.
In our series of 100 cystometrograms on 70 children with a variety of urinary disorders, there were 25 cases of clinically and radiologically established megaureter. Of these, 13 had a cystometric capacity greater than $400 \mathrm{ml}$. and 12 had normal cystometrograms. Among the 13 instances of the megauretermegacystis syndrome thus defined by cystometrography, eight cases also showed the typical clinical picture as described below. This syndrome, as defined by Williams (1958), is found in children of either sex who present with symptoms of urinary infection, renal failure, or abdominal pain. A distended bladder is palpable on repeated occasions, and large volumes of urine may be held for long periods, with little or no discomfort. Micturition proceeds without difficulty, except during episodes of acute retention due to infection, but a large residue remains. The bladder may still be palpable after double, or even triple, micturition. Cystoscopy reveals a smooth-walled bladder with widely dilated ureteric orifices which may, however, be seen to contract down at intervals. A feature of many of these cases is the massive reflux occurring at comparatively low intravesical pressures. The retrograde pyelogram shows a large bladder, vast, tortuous ureters, and bilateral hydronephrosis.

The cystometric capacity, which may be considerably in excess of the true bladder capacity, is very large indeed (450-1,700 ml.), while the filling curve conforms to the pattern described in the 'aparasympathetic' bladder, i.e., large volume, high terminal pressure, and diminished spontaneous detruser activity (Swenson and Fisher, 1955).

This group therefore corresponds to the megacystis of Swenson and the 'primary megaloureter' of Saintu. The two cases described below are of this type.

\section{CASE REPORTS}

CASE 4 L.F., a girl, was admitted to hospital at the age of 6 months with an infected flexural eczema. While in the ward she had several bouts of fever due to urinary infection with Esch. coli and was transferred for investigation of the urinary tract.

A crystogram showed enormous dilated ureters, a large bladder, and gross bilateral hydronephrosis. Free reflux up the ureters was apparent even when the bladder was only partly filled. On cystoscopy the bladder wall was smooth and the ureteric orifices were widely dilated. The lower ends of both ureters were observed to contract vigorously. A micturating cystogram showed that the bladder emptied completely but that a part of the volume refluxed up the ureters. The bladder gradually refilled from above giving rise to a large 'false' residual volume. Recurrent episodes of urinary infection followed over a period of years. On several occasions it was noted that the child's bladder was palpable up to the umbilicus. 
There was no pain or discomfort, and she passed a large volume of urine without difficulty. The bladder, however, was still palpable and remained so, even after double micturition.

A wedge resection of the posterior bladder neck was done to reduce the outlet resistance. It was thought that the procedure might improve drainage even though there was no difficulty in passing urine, and no undue prominence of the bladder neck. She left the hospital with a blood urea level of $\mathbf{4 0} \mathrm{mg} . \%$ and a clear urine.

Five months later she was re-admitted semi-comatose and uraemic. Death followed from bronchopneumonia at the age of 5 years and 7 months.

At necropsy a haemorrhagic bronchopneumonia, bilateral hydronephrosis, and chronic pyelonephritis were found. Both ureters were thickened, enormously dilated, and tortuous. The bladder measured $6 \times 4 \times 3.5 \mathrm{~cm}$. after fixation. It was smooth walled except for the mucous membrane of the trigone which was thrown into irregular folds. There was some increased thickness of the wall, but no trabeculation or prominence of the bladder neck. The ureteric orifices were drawn upwards and outwards and were widely patent. The urethra was normal.

CASE 5 V.C., a girl, was admitted at the age of 5 years 7 months with a history of failure to thrive and poor appetite for the past three and a half years. Her doctor had noted a bladder palpable at the umbilicus on several occasions and the fact that a large residual volume of urine remained after micturition. Shortly before admission she had developed dysuria, pain in the left loin, and gross pyuria.

A cystogram showed free reflux up grossly dilated ureters and bilateral hydronephrosis. On cystoscopy the bladder was large and smooth walled with widely gaping ureteric orifices. The bladder neck was relaxed and there was no urethral obstruction. The child was discharged on Gantrisin and a régime of double micturition, but a year later she was re-admitted with abdominal pain and pyrexia after several episodes of acute retention.

It was decided to replace the right ureter by a loop of ileum. This was done and the continuity of the bowel re-established by an end-to-end anastomosis. The excised portion of ureter continued to contract vigorously when tested in vitro, with the peristaltic wave commencing at the lower end and travelling upwards towards the pelvis.

Five days after the operation she developed abdominal distension and paralytic ileus followed by an incisional hernia. On re-opening the abdomen pus was found in the peritoneal cavity and a leak of urine from the lower ureteric anastomosis. This was repaired, but the ileus persisted and a further leak of urine developed around the drainage tube. The abdomen was again re-opened and both anastomoses appeared to be separating. The intestinal anastomosis was oversewn and a drainage tube put down. The child died on the eleventh post-operative day at the age of 6 years.

At necropsy a generalized acute peritonitis with widely distributed fibrinous exudate in the peritoneal cavity was $\vec{\sigma}$ found. The right ureter had been resected from below the renal pelvis to a point $1 \mathrm{~cm}$. above the bladder. It had been replaced by a segment of ileum but the anastomosis $\hat{N}$

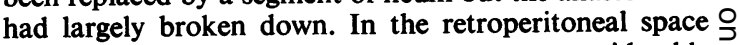
around the substitute ureter there was a considerable inflammatory exudate.

The kidneys showed a severe suppurative pyelonephritis and the left ureter was tortuous and widely dilated. $\overrightarrow{0}$ The bladder was thick walled, but without trabeculation, $\mathscr{f}$ and measured $5 \times 6 \times 7 \mathrm{~cm}$. after fixation. Both ureteric orifices were patent to a large probe. There was no abnormality of the bladder neck or the urethra.

These two cases were submitted to a quantitative histological study of the autonomic nervous system, as well as three controls and six other cases listed in Table I.

\section{METHODS AND MATERIAL}

At necropsy the entire urinary tract was removed en? bloc after injection (per urethram) with $10 \%$ formolo saline. The bladder was taken, together with the urethra, lower ureters, and the anterior wall of the vagina in the female, and the prostate, seminal vesicles, and anterior wall of the rectum in the male. No attempt was made to dissect the specimen or to clean it up by removingo adventitial connective tissue. Each bladder was halved,

TABLE I

DETAILS OF CONTROLS AND PATIENTS IN PRESENT SERIES

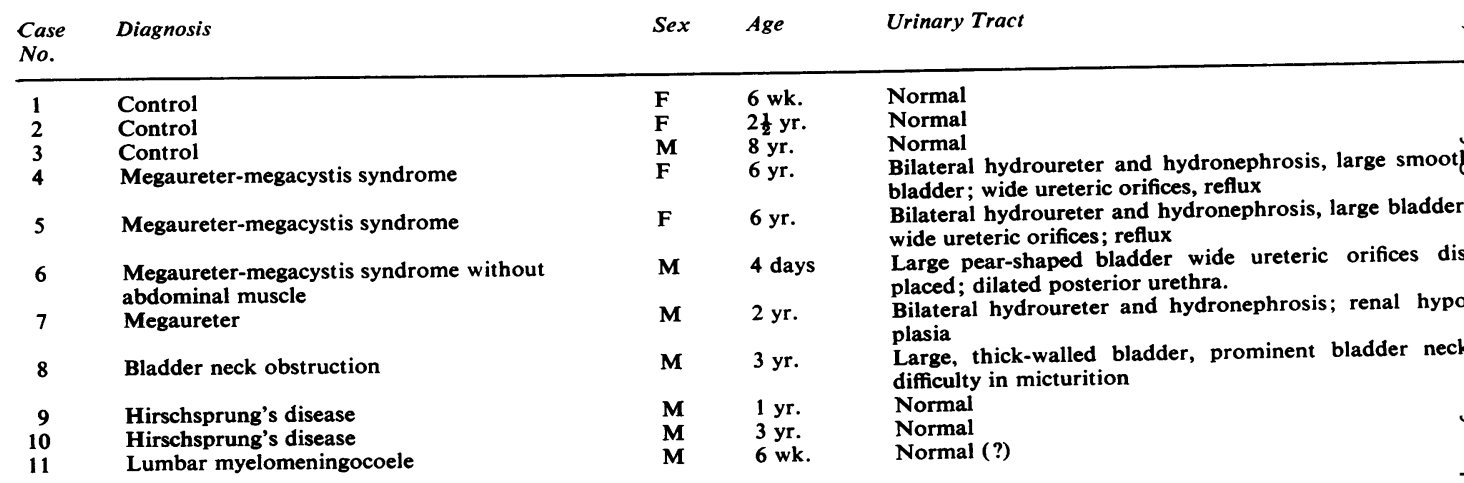

11 Lumbar myelomeningocoele

6 wk. Normal (?) 
and one half embedded in a single large paraffin block. This was subsequently subdivided into smaller blocks, if necessary.

To map out the normal distribution of ganglia, the bladder of a newborn female infant was serially sectioned, and $10 \mu$ sagittal sections were cut, starting from the midline. Every fifth section was mounted and stained with haematoxylin and eosin. A second set of slides was prepared, stained for Nissl material with thionin. A projection drawing $(\times 20)$ was made of every twentieth section and the ganglia seen in 20 successive sections were marked on each tracing. Each drawing, therefore, represented the ganglia in $1 \mathrm{~mm}$. thickness of bladder. The slides were scanned under the $\frac{1}{3}$ objective and ganglion cells confirmed under the $\frac{1}{6}$ in. objective. The drawings were made on cellophane sheets which were superimposed to give a three-dimensional impression of the distribution of ganglion cells in the bladder.

From a study of this distribution the following sampling method was decided upon. Each hemi-bladder was serially sectioned in the sagittal plane. One section in each millimetre was stained with haematoxylin and eosin and one with thionin. Outline drawings of each were made. The sections were scanned, the number of ganglion cells counted, and the position of the ganglia marked on the corresponding drawing.

In addition to a total count the number of cells in each of three zones was noted separately. 1 The adventitia at the base of the bladder, which includes ganglia in the adventitia of the trigone and at the lower end of the ureters, and also those around the prostate, seminal vesicles, and vesico-rectal septum in the male and the vesico-vaginal septum in the female; 2 the adventitia and subserosal layer of the remainder of the bladder; and 3 the muscularis.

Paraffin embedding and treatment of the tissue in bulk resulted in considerable shrinkage in some of the preparations. For cytological studies smaller blocks were taken and treated by double embedding.

\section{DISTRIBUTION OF GANGLION CELLS}

Our findings are largely in agreement with the description of the nerve supply of the bladder given by Stöhr (1928).

The vesical plexus forms a dense network of thick fibres in the adventitia at the base of the bladder. It is closely related to the lower end of the ureters, the lateral part of the trigone, and the adjacent parts of the lateral wall of the bladder. Nerve bundles in the subserous coat pass from the plexus medially towards the midline, anteriorly to the urethra, and superiorly to the apex. Large nerve trunks pass upwards in the subserous layer of the ureters. The network of nerves extends over the prostate, seminal vesicles, vas deferens, and into the vesico-rectal septum in the male and between the vagina and bladder in the female. Large nerve bundles traverse the muscularis, and in Bielchowsky silver preparations fine fibres are seen to pass from these nerves and to form a secondary and tertiary plexus. An abundant network of nerve fibres is also seen in the submucosa, the bundles being somewhat smaller than in the muscularis.

By far the greatest concentration of ganglion cells is found in the vesical plexus at the base of the bladder. The cells are grouped in ganglia of varying size lying between the nerve bundles. Collections of neurones may also be seen within some of the larger nerve trunks. Small ganglia are sparsely scattered throughout the subserosa and adventitia of the remainder of the bladder and in the muscularis, mainly in the outer third. Single isolated cells are also seen in this layer, and very occasionally a small group of cells is observed in the submucosa closely applied to the inner border of the muscularis.

The ganglion cells vary from large multipolar neurones with a deeply stained, well-rounded cell body and prominent nucleolus, to smaller cells with crenated edge, pale cytoplasm, and less well-defined nuclear characteristics. Both have dust-like particulate Nissl material in their cytoplasm. In the larger ganglia the neurones are surrounded by satellite cells forming a well-defined capsule, while in smaller ganglia they are embedded in a loose glial supporting tissue.

\section{CELL COUNTS}

The number and distribution of ganglion cells in the three normal bladders is shown in Figures 1, 2, and 3.

In the adventitia at the base of the bladder few cells are seen in the most medial sections, as the

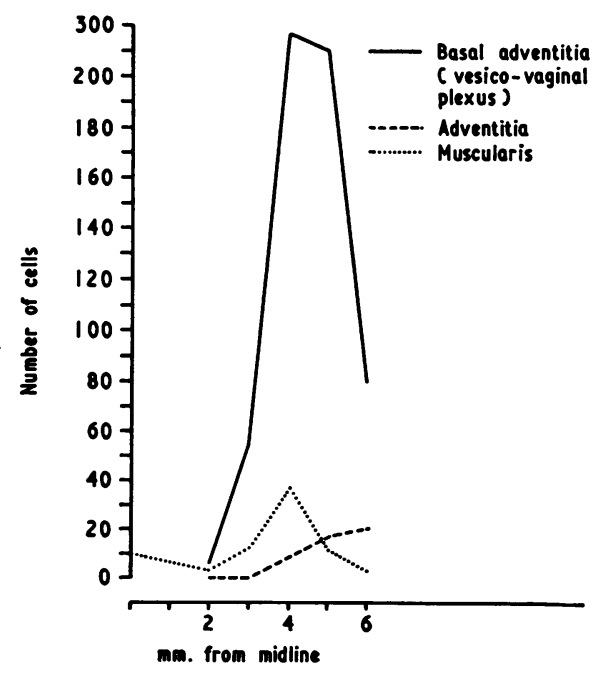

FIG. 1. Control, female, aged 6 weeks. 


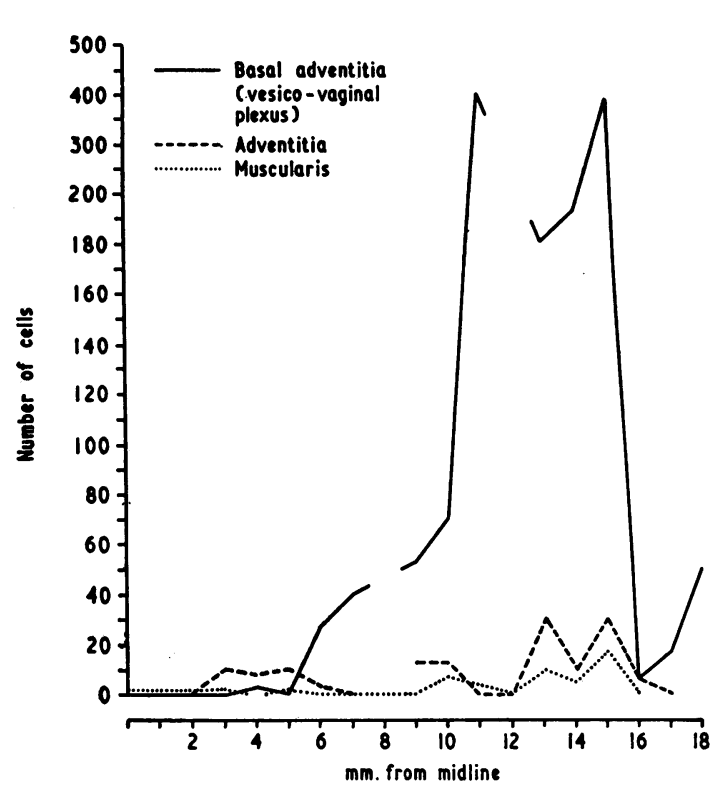

FIG. 2. Control, female, aged $2 \frac{1}{2}$ years. Gaps in the curves indicate lack of continuity in the serial counts.

vesical plexus does not extent to the midline. Laterally, however, large ganglia containing masses of ganglion cells make their appearance.

The largest ganglia are located in the adventitia of the bladder wall adjacent to the lower end of the ureters. There are smaller collections of cells in the lateral part of the trigone, the vesico-vaginal septum in the female and around the seminal vesicles and prostate in the male. Between one and 1,100 cells may be counted in a single section.

In the adventitia of the remainder of the bladder the cell count varied from 0 to 40 cells in a complete sagittal section. Over $80 \%$ of the counts contained fewer than 10 cells per section, and in one half of the sections no cells were found in this layer.

In the muscularis the counts were similarly low. The range was 0-35 cells per section.

The limitations inherent in a count of this sort must clearly be borne in mind. The vagaries of staining, the difficulty of counting cells in the densely packed larger ganglia, and the problem of the identification of neurones, particularly of the smaller and less well-differentiated types, will all affect the accuracy of the count. In some of the material the length of fixation and the relatively drastic treatment involved in embedding and processing large blocks produced considerable shrinkage of the neurones.

An additional difficulty is that the vesical plexus

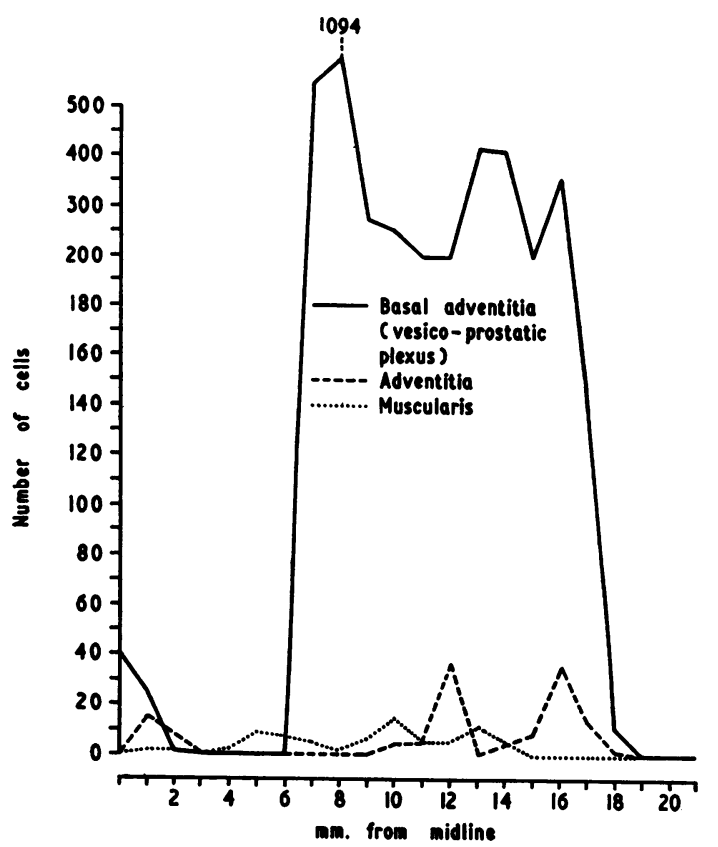

FIG. 3. Control, male, aged 8 years.

is continuous with the general pelvic plexus, and its limits cannot be accurately defined. The number of $\frac{2}{8}$ cells counted in the basal adventitia, therefore, is $\Rightarrow$ merely an indication that a greater or lesser part of $\stackrel{3}{3}$ the plexus has been included in the section. The distinction, too, between the ganglia at the 'base of the bladder' and the 'adventitia of the remainder of the bladder', although very useful, is purely? arbitrary.

Nevertheless, the method is adequate for the purpose. To be at all meaningful, the reduction in ganglion cells would have to be very marked, with only a few small ganglia in the vesical plexus and은 the virtual absence of neurones from the subserosal and muscular layers.

\section{RESULTS}

Ganglion cell counts in the two cases of megaureter- $\omega$ megacystis syndrome are shown in Figures 4 and $5: ?$ Large ganglia containing $300-400$ cells per sectione were found in the vesical plexus. In the adventitia and the muscularis between 0 and 40 cells per layer. were counted in complete sagittal sections of the bladder. The total number of cells counted in each $\frac{\text { P }}{\mathrm{D}}$ layer is not statistically different from that in the? normal curves $(P>0 \cdot 1)$. (Two sample $t$ tests weree based on the range of Moore 1957.) Similarly, counts (Figs. 6 and 7) from the cases of bladder necko 


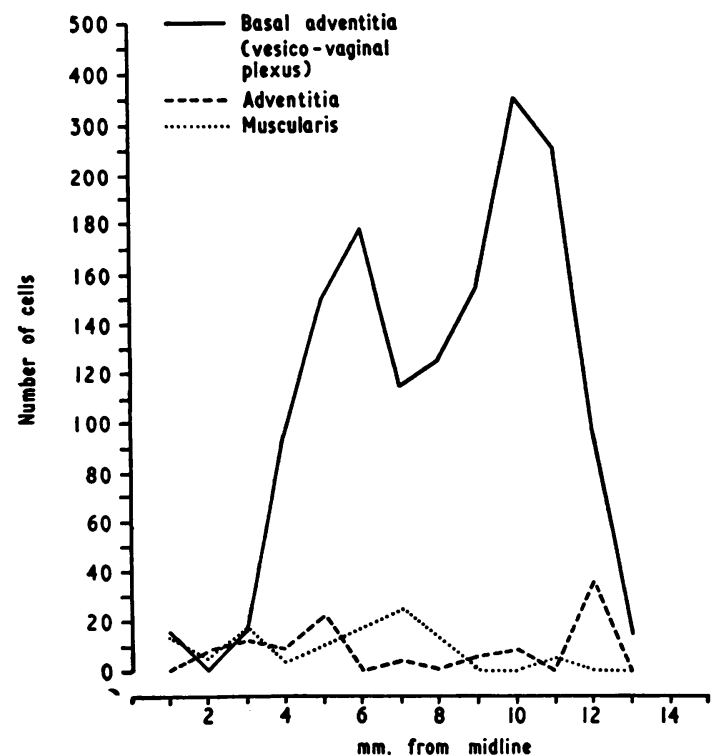

FIG. 4. Megaureter-megacystis syndrome, female, aged 6 years.

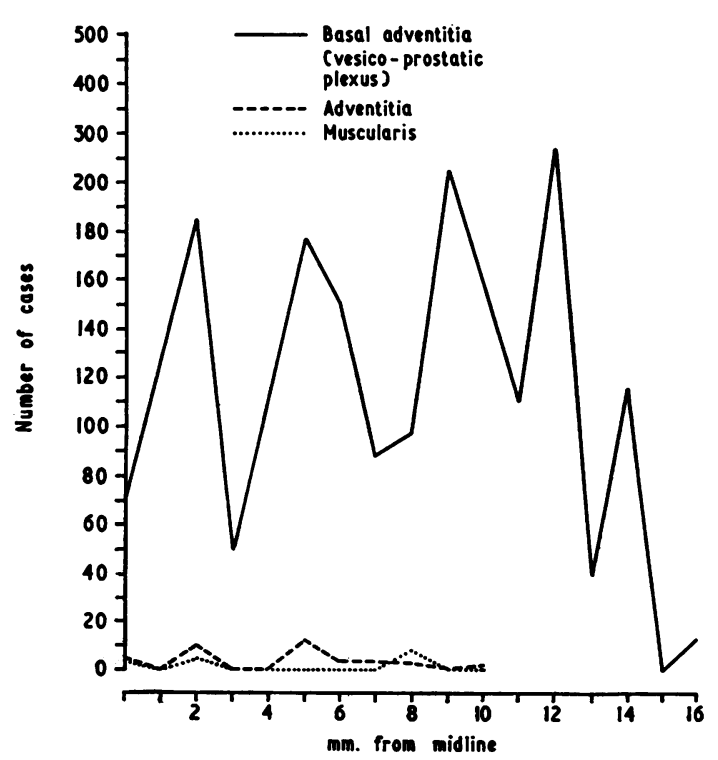

FIG. 6. Megaureter, male, aged 2 years.

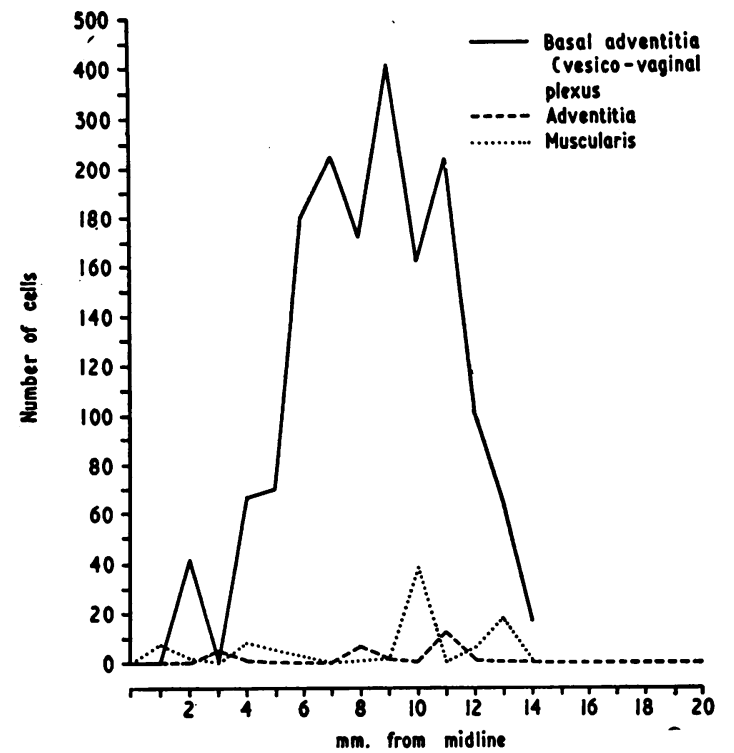

FIG. 5. Megaureter-megacystis syndrome, female, aged 6 years.

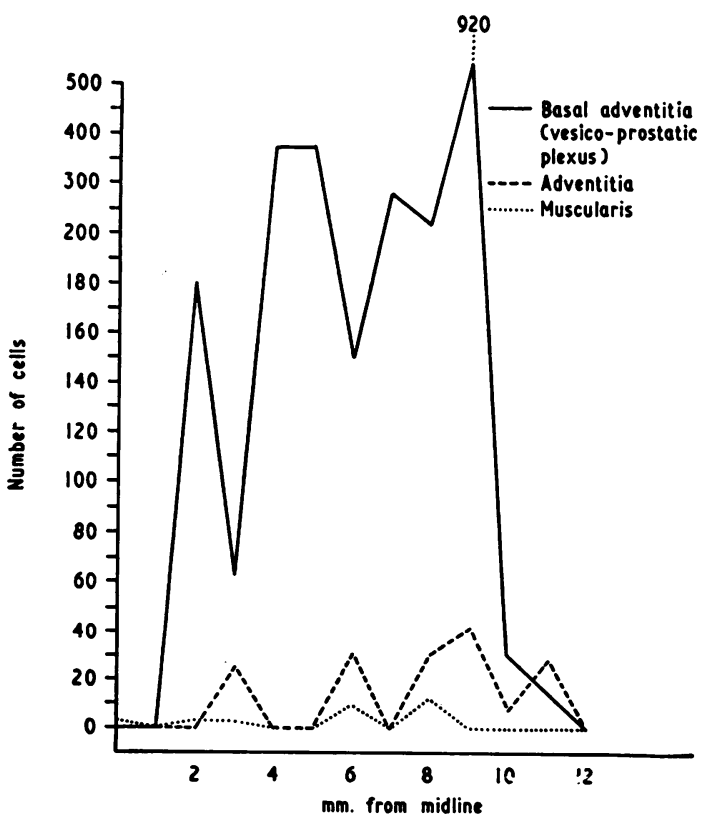

FIG. 7. Bladder neck obstruction (urethral fibro-elastosis), male, aged 3 years. 


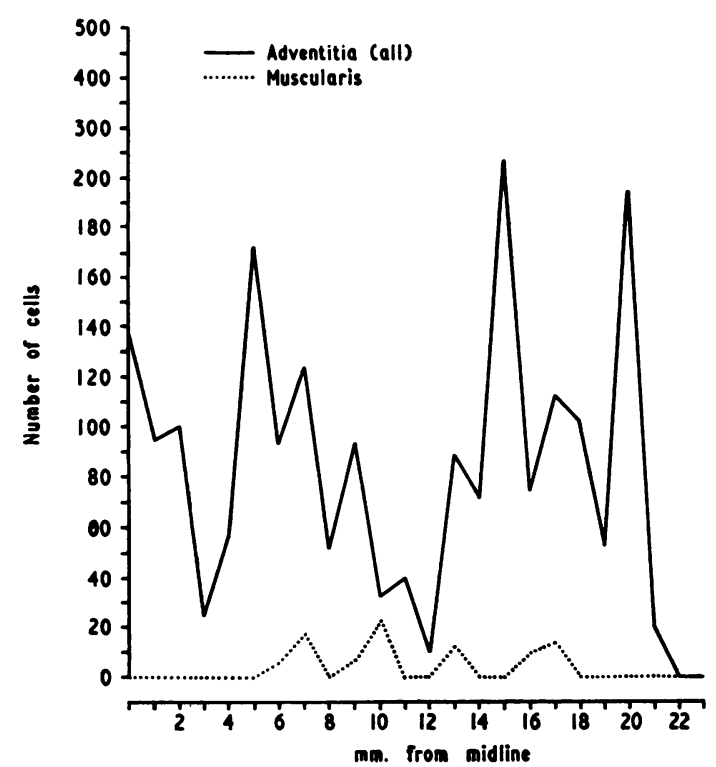

FIG. 8. Absent abdominal muscles, male, aged 4 days.

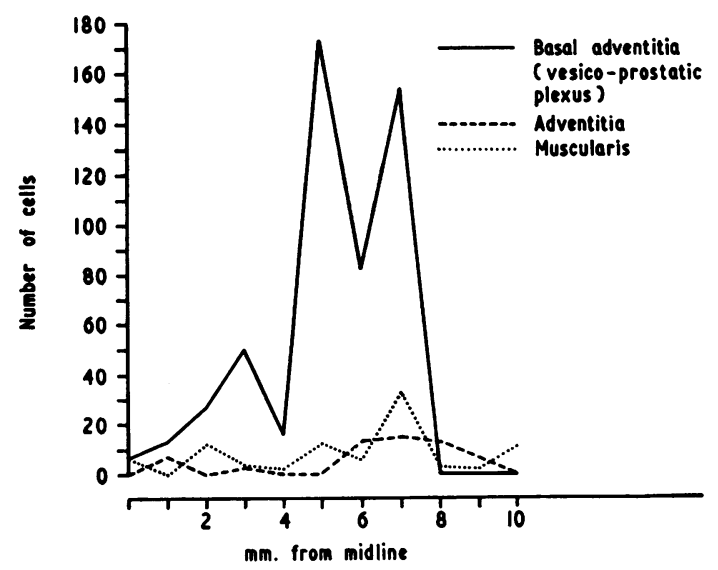

FIG. 9. Hirschsprung's disease, male, aged l year.

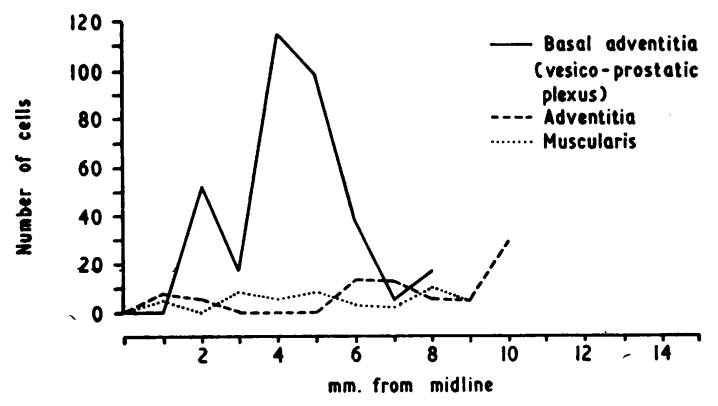

FIG. 10. Hirschsprung's disease, male, aged 3 years.

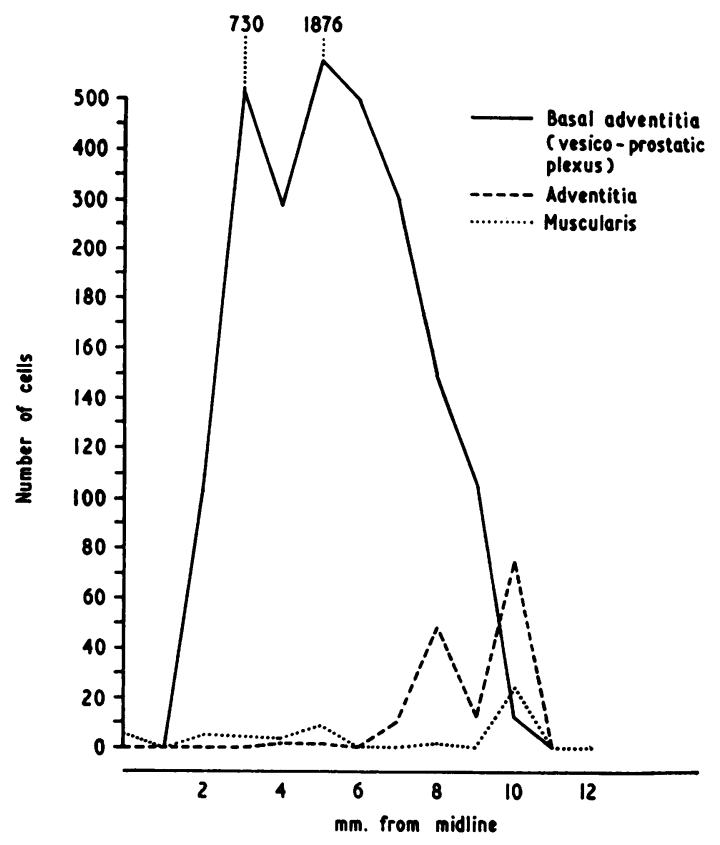

FIG. 11. Neurogenic bladder (lumbar myelomeningocoele), male, aged 6 weeks.

obstruction and of megaureter are comparable with those in normal bladders.

Large ganglia were seen in the megabladder associated with absent abdominal muscles, but the distribution was unusual (Fig. 8). This was presumably related to the highly abnormal anatomy of that bladder. It was a large pear-shaped structure with a flattened base lying up against the sacrum and an apical attachment to the umbilicus. The ureteric orifices were located on the lateral walls anteriorly and widely separated. The ganglia were $\frac{D}{0}$ widely distributed over a large area on the lateral and superior surface, extending up towards the apex $\mathrm{N}$ in the midline and around the lower ureters laterally. $N$ Many of the neurones were primitive in appearance and some showed striking rosette formation.

In the two cases of Hirschsprung's disease studied 2 the normal number of intramural cells were seen. $\stackrel{\circ}{\subset}$ Large ganglia were also found in the basal adventitia $\mathbb{\Phi}$ (Figs. 9 and 10). The relatively low peaks in this? layer are accounted for by the operative procedures these children had been subjected to, and the difficulties of dissection in this area at necropsy.

The cell count in the bladder from a case with $a \stackrel{\square}{\varrho}$ myelomeningocoele and spina bifida was normal (Fig. 11). 


\section{DISCUSSION}

These results do not support the view that there is a diminution of the intravesical neurones in megaureter.

In assessing reports on the absence of ganglion cells the peculiarities of the cell distribution must be borne in mind.

A complete sagittal section which does not pass through one of the large ganglia at the base of the bladder may contain very few cells. If smaller blocks are taken at random a large proportion may be expected to contain no ganglion cells at all, while in a large distended bladder the number of cells per section will be further reduced in proportion to the cube of the increase in the radius.

The chance of a large ganglion being seen depends entirely upon how much of the vesical plexus is included in the block. If the adventitia at the base of the bladder is removed in dissection, as may easily occur, most of the large ganglia will be stripped with it. In addition it must be remembered that most of the dilatation in the bladder takes place at the fundus, while the base remains relatively fixed. If small blocks of the bladder wall are taken at random, the chances of one of them passing through tissue at the base decrease as the organ is distended. It becomes progressively less likely that a large ganglion will be included in any given section.

In suitable sections the neurones were normal, and there were no signs of reactive inflammatory change in the supporting tissue of the ganglia or of any abnormality in the nerve trunks. Thus there was no evidence found of reactive changes such as may result from loss of neurones.

BLADDER FUNCTION IN MEGACYSTIS The argument for regarding bladder function in megacystis as 'aparasympathetic' is based upon the appearance of the cystometrogram. The most important features are the atonic filling curve, high terminal pressure, and there is a reduction in spontaneous detrusor activity during filling. The powerful involuntary contraction which may terminate the test normally is absent. The interpretation of this curve that has been advanced is that the neurones forming the final common path of the parasympathetic motor outflows are defective, and in consequence reflex detrusor tone is minimal and emptying contractions weak. The final result is a large bladder with high terminal pressure which is held to be responsible for the dilatation of the ureter (Swenson and Fisher, 1955).

It is well known, however, that the atonic cystometric curve is a relatively non-specific end-result and can be brought about in a number of different ways. A lesion in any component of the sacral reflex (either sensory or motor) might give rise to a cystometrogram of this type. A primary defect of muscle, or long-continued distension, as in chronic retention from any cause, may do the same. Finally, supranuclear inhibitory influences, at the level of consciousness or below, must be considered as possible causes of a large atonic bladder. Unfortunately, analysis of the cystometric curve itself does not allow us to distinguish between these various alternatives.

Using cineradiography, Edwards (1957) found that during voluntary micturition the bladder in these cases contracts well and empties completely. Some of the fluid, however, refluxes up the ureters, which form a reservoir from which the bladder slowly refills. A false residuum is therefore formed which is not due to any defect in the motor neural pathway. This suggests that the bladder disturbance may be entirely secondary to the incompetence of the uretero-vesical mechanism.

That the power of the muscle itself is undiminished is suggested by the reaction shown in one of these cases to an intramuscular injection of carbachol. It produced a sudden rise in the intravesical pressure to over $30 \mathrm{~cm}$. of water and reduced the cystometric capacity from 425 to $250 \mathrm{ml}$.

Whatever the cause of the megaureter-megacystis syndrome may ultimately be found to be, there are at present no unequivocal grounds for regarding the parasympathetic supply as defective.

MEGAURETER AND HIRSCHSPRUNG'S DISEASE The association of these two conditions has been reported by a number of authors. Hepler (1937) and Campbell (1951) each report one case. Of 11 cases of megaoesophagus investigated by Etzel (1942), three were said to have megaureter and two megacolon. The association of aganglionic colon, phaeochromocytoma, neurofibroma, and megaureter in a third was noted by Shocket and Teloh (1957). They attributed these to a widespread lesion of the neural crest. In the earlier accounts the diagnosis of Hirschsprung's disease was not confirmed histologically, but in a series of proven cases, Swenson reported $3 \%$ with megaureter. Fifty per cent were said to have bladder capacities larger than normal, but no details of the volume were given.

At this hospital no such association has been observed. In 278 cases of histologically confirmed Hirshcsprung's disease not a single instance of megaureter was found. Twenty-five of the children had pre-operative intravenous pyelograms and in all cases the ureters were open to inspection at operation or necropsy.

Twelve cases came to necropsy and no abnor- 
mality of the genito-urinary system was found. In a few instances, however, urinary symptoms developed after operation. The ganglion cell counts in two cases were normal as indicated above. No comparable quantitative data have hitherto been recorded in the literature. Boggs and Kidd (1958), however, found normal perivesical and periprostatic ganglia in random sections of two cases of Hirschsprung's disease of the long segment variety.

EMBRYOLOGICAL CONSIDERATIONS The aganglionic segment in Hirschsprung's disease is of variable length, and may extend well above the area supplied by the pelvic parasympathetic nerves. It cannot therefore be regarded purely as a defect of the sacral parasympathetic system.

The intramural ganglia in the bowel are thought to develop by the differentiation or migration of neurones in a cranio-caudal direction (Bodian, Carter, and Ward, 1951), a view also held by van Campenhout (1931) in the chick and by Hüther (1954) in the human embryo; Hüther, however, suggests a different mechanism for the rectum. Recent experimental evidence has thrown an interesting light on the relative independence of the cranio-caudal development of neurones from that of the pelvic plexus. According to Yntema and Hammond (1953) the intramural ganglia of the gut are derived from the cranial neural crest. These cells migrate cranio-caudally and take part in the formation of the plexuses of Auerbach and Meissner all the way down to the terminal rectum. The neurones of the abdominal and pelvic ganglia (including the vesical) originate in the neural crest of the trunk.

The extirpation of the vagal neural crest in a chick embryo of 7 to 10 somites resulted in an aganglionic terminal segment in the bowel which varied in length with the timing and extent of the excision. The preganglionic fibres to the gut and the sympathetic and pelvic ganglia developed normally, an interesting example of a lesion similar to Hirschsprung's disease in distribution, in which the vesical ganglia were not affected. Conversely when the neural crest of the trunk was extirpated the pelvico ganglia failed to develop, but the intramural ganglia of the terminal bowel were normal.

Until more is known of the aetiology of Hirsch-o sprung's disease the possibility of similar lesions in흘 other organs cannot be excluded. These findings, $\frac{\bar{s}}{\bar{S}}$ however, illustrate that from the embryological $\varnothing$ point of view there is no reason for assuming thato the absence of ganglia in the terminal bowel must ${ }^{\text {s }}$ necessarily be associated with a similar defect in. the bladder.

We are indebted to the Research Committee of The Hospital for Sick Children for the research fellowship? given to $\mathrm{S}$. L. enabling us to carry out the study reported $\vec{\sigma}$ here. We are also grateful to Mr. D. Innes Williams for $A$ his support with the cystometrographic investigations. $\omega$ The Department of Medical Illustration has kindly N helped us with the graphs.

\section{REFERENCES}

Bodian, M. (1957). Brit. J. Urol., 29, 393.

- Carter, C. O., and Ward, B. C. H. (1951). Lancet, 1, 302.

Boggs, J. D., and Kidd, J. M. (1958). Pediatrics, 21, 261.

Campbell, M. (1951). Clinical Pediatric Urology, p. 794. Saunders, Philadelphia and London.

Edwards, D. (1957). Brit. J. Urol., 29, 410.

Etzel, E. (1942). Amer. J. med. Sci., 203, 87.

Henley, W. L., and Hyman, A. (1953). Amer. J. Dis. Child., 86, 795.

Hepler, A. B. (1937). J. Amer. med. Ass., 109, 1602.

Hurst, A. F., and Gaymer-Jones, J. (1931). Brit. J. Urol, 3, 43.

Hüther, W. (1954). Beitr. path. Anat., 114, 161.

Learmonth, J. R. (1931). Brain, 54, 147.

Lewis, E. L., and Kimbrough, J. C.(1952). Sth. med.J. (Bgham., Ala.), 45,171

Moore, P. G. (1957). Biometrika, 44, 482.

Prosser, C. L., Smith, C. E., and Melton, O. E. (1955). Amer. J. Physiol., 181, 651.

Ruland, L. (1956). Z. Urol., 49, 197.

Shocket, E., and Teloh, H. A. (1957). Amer. J. Dis. Child., 94, 185,

Stöhr, P. (1928). In Möllendorff's Handbuch der Mikroskop. Anat? des Mensch, vol. 4. Springer, Berlin.

Swenson, O., MacMahon, H. E., Jacques, W. E., and Campbell, J. S. (1952). New Engl. J. Med., 246, 41.

and Fisher, J. H. (1955). Ibid., 253, 1147.

Trassord, H. S. (1959). Brit. med. J., 1, 149.

van Campenhout, E. (1931). Arch. Biol. (Liège), 42, 479.

Williams. D. (1958). In Urology in Childhood (Handbuch de Urologie $\mathrm{O}$ Encyclopedia of Urology, edited by C. E. Alkin et al., Band 15), pp. 57-65. Springer, Berlin.

Yntema, C. L., and Hammond, W. S. (1953). Anat. Rec., 115, 382. 